\title{
THÀNH LẬP BẢN ĐỒ HỆ SINH THÁI ĐẤT NGẬP NƯớC TỶ LÊ 1:100.000 ĐỒNG THÁP MƯỜI TRÊN CƠ SỞ TIẾP CẬN CẢNH QUAN
}

\author{
NGUY ẼN THANH THỦY \\ Viện Khoa học Đo đạc và Bản đồ
}

\section{Tóm tắt:}

Bản đồ hệ sinh thái đất ngập nước (HSTĐNN) là dũ liệu đầu vào cho công tác đánh giá mưc độ đa dạng sinh học, các chức năng, dịch vụ, các áp lực rủi ro mà hệ sinh thái phải đối diện; xác định các hệ sinh thái bị suy thoái, tù đó làm cơ sở xác định các hệ sinh thái cần ưu tiên bảo vệ, phục hồi. Bài báo trình bày phưong pháp thành lập bản đồ hệ sinh thái đất ngập nước tỷ lệ 1:100.000 khu vực Đồng Tháp Muời phục vu lập quy hoạch và quản lý đất ngập nuớc trong phạm vi cấp vùng, liên tỉnh trên cơ sở tiếp cận cảnh quan với các yếu tố cấu thành là địa chất, thổ nhuõong, địa hình - địa mạo, khi hậu - khi tuợng, thuỷ văn - hải văn, thảm thực vật và hiện trạng sủ dụng đất.

\section{1. Đặt vấn đề}

Hệ sinh thái (HST) là tổ hợp của quần xã sinh vật với môi trường vô sinh mà quần xã đó tồn tại, trong đó các hệ sinh vật tương tác với nhau và với môi trường để tạo nên chu trình vật chất và chuyển hoá năng lượng $[7,8]$. Sinh thái học các thủy vực là một bộ phận của sinh thái học chung, đối tượng nghiên cứu là mối quan hệ của thuỷ sinh vật với môi trường nước, nơi diễn ra các hoạt động sống của sinh vật ở các mức độ khác nhau, từ cá thể, quần thể đến quần xã sinh vật trong hệ sinh thái. Các hệ sinh thái của thủy quyển rất đa dạng, gồm hệ thống dòng chảy và hồ nước ngọt, đầm phá ven biển, các biển và đại dương với những bãi triều các rạn san hô có những đặc trưng về hình thái - cấu tạo, điều kiện địa chất - địa mạo, khí tượng - thuỷ văn, sự phân bố các quần xã sinh vật và những cơ chế đặc thù trong quá trình hình thành và phát triển các dạng tài nguyên trong quan hệ tương tác giữa địa quyển, khí quyển, thuỷ quyển và sinh quyển trên bề mặt hành tinh.

Cảnh quan địa lý là một địa tổng thể được phân hóa trong phạm vi một đới ngang ở đồng bằng và một đai cao ở miền núi, có một cấu trúc thẳng đứng đồng nhất về nền địa chất, về kiểu địa hình, kiểu khí hậu, kiểu thủy văn, về đại tổ hợp thổ nhưỡng và đại tổ hợp thực vật và bao gồm một tập hợp có quy lật những dạng địa lý và những đơn vị cấu tạo nhỏ khác theo một cấu trúc ngang đồng nhất. Cảnh quan Việt Nam được phân chia thành 9 cấp là Hệ thống cảnh quan $\rightarrow$ Phụ hệ cảnh quan $\rightarrow$ Lớp cảnh quan $\rightarrow$ Phụ lớp cảnh quan $\rightarrow$ Kiểu cảnh quan $\rightarrow$ Phụ kiểu cảnh quan $\rightarrow$ Hạng cảnh quan $\rightarrow$ Loại cảnh quan $\rightarrow$ Cảnh quan [5]. Trong cấu trúc mỗi loại cảnh quan tính sinh thái đã được thể hiện từ sự kết hợp của các nhân tố môi trường và quần xã sinh vật nên thuật ngữ "cảnh quan" và "sinh thái cảnh quan" được coi là đồng nhất [1]. Việc ứng dụng tiếp cận sinh thái cảnh quan trong nghiên cứu về đất ngập nước đã được áp dụng và thực hiện 
nhiều trên thế giới cũng như ở Việt Nam $[1,6] \ldots$

Theo Công ước Ramsar thì các vùng đất ngập nước là "Những vùng đầm lầy, vùng lầy, vùng than bùn hay vùng nước tự nhiên hay nhân tạo, thường xuyên hay tạm thời với nước tĩnh hay chảy, nước ngọt, lợ hay mặn bao gồm các khu vực nước biển có độ sâu không quá 6 mét so với triều kiệt”; "Có thể hợp nhất với các vùng ven sông, duyên hải ven biển tiếp giáp vùng đất ngập nước và các đảo hay vùng biển nước sâu không quá 6 mét so với triều kiệt trong vùng đất ngập nước". Công ước cũng nhấn mạnh rằng toàn bộ hệ thống các hồ, sông cũng nằm trong định nghĩa về các vùng đất ngập nước Ramsar mà không tính đến độ sâu của chúng. Các vùng đất ngập nước được xác định theo hệ thống phân loại đất ngập nước với nhiều cách tiếp cận khác nhau. Ở Hoa Kỳ đất ngập nước được phân loại dựa trên các yếu tố ảnh hưởng như thuỷ lực, địa mạo, hoá học hay sinh học; ở Canada được phân chia dựa trên nguồn gốc chung của hệ sinh thái và đặc điểm tự nhiên của môi trường đất ngập nước (địa mạo, thuỷ văn và đất; hình thái của quần xã thực vật); Tổ chức bảo tồn thiên nhiên quốc tế (IUCN) phân chia dựa trên quan điểm sinh thái phát sinh (đặc trưng nước mặn, ngọt; độ sâu ngập nước và địa mạo; hiện trạng sử dụng đất); Uỷ hội sông Mêkông (MRC) phân chia dựa trên thảm thực vật (các quần xã thực vật) và sử dụng đất [9]. Quyết định 1093/QĐ-TCMT năm 2016 của Tổng cục Môi trường quy định đất ngập nước ở Việt Nam được phân loại dựa trên các yếu tố thuỷ - hải văn, địa hình, địa mạo, điều kiện thổ nhưỡng, mức độ tác động của con người và ảnh hưởng của các yếu tố biển, lục địa); điều kiện địa hình, địa mạo, thuỷ - hải văn (chế độ ngập nước và thuỷ hoá), thổ nhưỡng (cấu trúc đất và địa hoá), thảm thực vật, hiện trạng sử dụng mặt đất và nước. Có thể thấy trong các nghiên cứu và quy định trên về phân loại đất ngập nước không có quy định nào đề cập một cách chính thức đến "hệ sinh thái đất ngập nước", song lại dựa trên các yếu tố hình thành nên môi trường vô sinh, hữu sinh cấu thành nên một hệ sinh thái. Gần đây nhất, nghị định số 66/2019/NĐ-CP là văn bản pháp luật đầu tiên đã giải thích về hệ sinh thái đât ngập nước: "Hệ sinh thái đất ngập nước là khu vực bao gồm quần xã sinh vật và các yếu tố phi sinh vật của một vùng đất ngập nước nhất định có tác động qua lại và trao đổi vật chất với nhau" nhưng chưa chỉ rõ các yếu tố phi sinh vật.

Từ những nghiên cứu trên, có thể hiểu các yếu tố chính hình thành nên hệ sinh thái đất ngập nước bao gồm: i) Địa chất; ii) Địa hình - địa mạo; iii) Điều kiện thuỷ văn - hải văn; iv) Khí hậu - khí tượng; v) Thổ nhưỡng; vi) Thảm thực vật. Yếu tố hoạt động nhân sinh tác động vào đất ngập nước để tạo ra các loại đất ngập nước nhân tạo có thể được thể hiện qua hiện trạng sử dụng đất.

Việc sử dụng cách tiếp cận sinh thái cảnh quan đã được áp dụng trong một số công bố ở trên thế giới và ở Việt Nam, tuy nhiên chưa có nghiên cứu nào đề xuất quy trình thành lập bản đồ hệ sinh thái đất ngập nước, đặc biệt là phải phù hợp với hệ thống phân loại đất ngập nước của Ramsar và của Việt Nam.

\section{Phương pháp luận}

Các thành phần chính hình thành nên cảnh quan sinh thái bao gồm địa chất, địa hình - địa mạo, khí hậu, thuỷ văn - hải văn, thổ nhưỡng, lớp phủ $[2,3,4]$, đây cũng là những thành phần cơ bản hình thành nên một hệ sinh thái. Chính vì vậy, bài báo này đã dựa trên cách tiếp cận sinh thái cảnh quan để thành lập bản đồ hệ sinh thái đất ngập nước. Các bước thành lập bản đồ hệ sinh thái đất ngập nước được thể hiện trong Hình 1. (Xem hinh 1) 


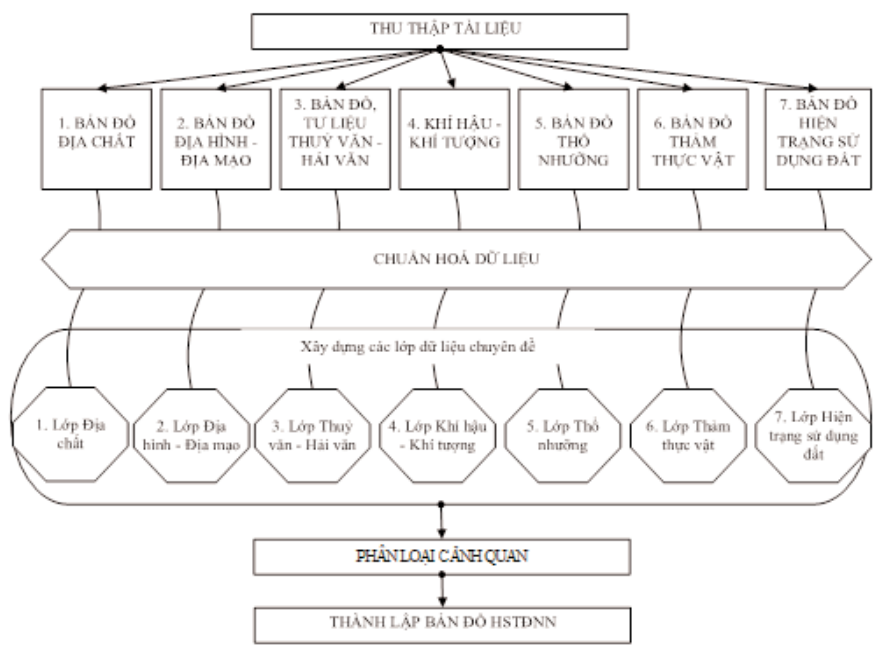

Hình 1: Quy trình thành lập bản đồ HSTĐNN tỷ lệ 1:100.000 theo tiếp cận cảnh quan

\section{Bước 1. Thu thập tài liệu}

Trong bước này, các tài liệu được thu thập bao gồm các tư liệu, tài liệu, dữ liệu bản đồ về địa chất; địa hình - địa mạo; thuỷ văn, hải văn; khí hậu, khí tượng; các số liệu, dữ liệu về quan trắc, điều tra về thổ nhưỡng; thảm thực vật; hiện trạng sử dụng đất... phục vụ cho việc không gian hoá, chuẩn hoá dữ liệu phục vụ xây dựng bản đồ hệ sinh thái đất ngập nước.

\section{Bước 2. Chuẩn hoá dũ liệu}

Trên cơ sở tài liệu, số liệu, dữ liệu ở các định dạng khác nhau như giấy, các tệp tin toạ độ, các dữ liệu bản đồ, cần tiến hành chuẩn hoá, không gian hoá về thông tin, thuộc tính, ranh giới theo yêu cầu của từng loại dữ liệu bản đồ tương ứng.

\section{Bước 3. Phân loại cảnh quan}

Tiến hành chồng xếp các lớp dữ liệu chuyên đề đã được chuẩn hoá để xác định các cấp phân vị cảnh quan ở tỷ lệ 1:100.000 được kế thừa từ kết quả của các nghiên cứu $[2,4,5]$ với 7 cấp (Hệ cảnh quan $\rightarrow$ Phụ hệ cảnh quan $\rightarrow$ Kiểu cảnh quan $\rightarrow$ Lớp cảnh quan $\rightarrow$ Phụ lớp cảnh quan $\rightarrow$ Kiểu cảnh quan $\rightarrow$ Phụ kiểu cảnh quan $\rightarrow$ Loại cảnh quan).
Buớc 4. Thành lập bản đồ hệ sinh thái đất ngập nước

Căn cứ kết quả phân loại cảnh quan ở bước trên, bài báo phân loại đất ngập nước quy định trong quyết định 1093/QĐ-TCMT ngày 22/8/2016 Hướng dẫn kỹ thuật phân loại đất ngập nước của Tổng cục Môi trường để xác định và đặt tên các hệ sinh thái đất ngập nước tương ứng.

\section{Kết quả thành lập bản đồ hệ sinh thái đất ngập nước khu vực Đồng Tháp Mười}

\subsection{Khu vục nghiên cứu}

Đồng Tháp Mười phân bố từ $105^{\circ} 11^{\prime} 8,4$ '”$106^{\circ} 25^{\prime} 51,4^{\prime \prime}$ kinh độ Đông và $10^{\circ} 16^{\prime} 28,9$ $11^{\circ} 01$ '58" vĩ độ Bắc, gồm các đơn vị hành chính thuộc Long An (huyện Tân Hưng, Vĩnh Hưng, Mộc Hoá, Tân Thạnh, Thạnh Hoá, Đức Huệ, và 2 xã thuộc huyện Bến Lức, 5 xã thuộc huyện Thủ Thừa), Đồng Tháp (huyện Hồng Ngự, Tân Hồng, Tam Nông, Thanh Bình, Cao Lãnh, Tháp Mười, thành phố Cao Lãnh) và Tiền Giang (huyện Cái Bè, Cai Lậy, Tân Phước), đây là một vùng trũng, nằm trọn vẹn trong bồn địa hạ lưu sông Cửu Long. Phía Tây và phía Nam được giới hạn bởi sông Tiền, phía Đông và phía Bắc là dải 
đất chuyển tiếp giữa phù sa cổ và mới, dọc biên giới Việt Nam - Campuchia dài $85 \mathrm{~km}$, phía Nam là Quốc lộ $1 \mathrm{~A}$. Diện tích khu vực khoảng 6.711,3 $\mathrm{km}^{2}$ chiếm $71 \%$ diện tích của cả 3 tỉnh Long An, Tiền Giang, Đồng Tháp. Đồng Tháp Mười có nhiều ý nghĩa về mặt bảo tồn đa dạng sinh học, chủ yếu tập trung ở vườn Quốc gia Tràm Chim, khu bảo tồn đất ngập nước Láng Sen, khu du lịch sinh thái Giáo Giồng, Xẻo Quýt...

\subsection{Dũ liệu}

Các dữ liệu đầu vào phục vụ thành lập bản đồ hệ sinh thái đất ngập nước được thu thập từ nhiều nguồn bao gồm: bản đồ địa chất khoáng sản, địa chất thuỷ văn tỷ lệ 1:200.000; bản đồ địa mạo tỷ lệ 1:200.000; bản đồ thổ nhưỡng tỷ lệ 1:100.000; bản đồ hiện trạng sử dụng đất tỷ lệ 1:100.000; bản đồ thảm thực vật (TTV) tỷ lệ
1:50.000; bản đồ phân loại đất ngập nước tỷ lệ 1:5.000 thuộc dự án (Viện Khoa học Đo đạc và Bản đồ, 2012); các dữ liệu khí tượng thuỷ văn giai đoạn 2005 - 2018 (Niên giám thống kê Long An, Tiền Giang, Đồng Tháp năm 2018); dữ liệu độ cao từ cơ sở dữ liệu nền địa lý tỷ lệ 1:2.000, 1:5.000; ảnh vệ tinh LandSat-8 chụp 11/2018...

\subsection{Kết quả}

Các loại bản đồ đã được thành lập từ các dữ liệu đầu vào ở trên (địa chất, địa mạo, thảm thực vật, sinh khí hậu, thổ nhưỡng, đặc điểm thuỷ văn, hiện trạng sử dụng đất) được chồng xếp bằng phần mềm ArcGIS 10.5, khái quát hoá, xác định loại cảnh quan, đánh số và trình bày bản đồ. Kết quả bản đồ phân vùng cảnh quan sinh thái khu vực Đồng Tháp Mười được trình bày trong Hình 2.

Bảng 1: Tiêu chí sử dụng cho phân loại hệ sinh thái đất ngập nước

\begin{tabular}{|c|c|c|c|c|c|}
\hline \multirow[b]{2}{*}{$\begin{array}{c}\text { Hệ } \\
\text { thống }\end{array}$} & \multirow[b]{2}{*}{$\begin{array}{c}\text { Hệ } \\
\text { thống } \\
\text { phụ }\end{array}$} & \multicolumn{3}{|c|}{ Các kiểu hệ sinh thái đất ngâp nước } & \multirow[b]{2}{*}{$\begin{array}{l}\text { Dữ liệu sử } \\
\text { dụng }\end{array}$} \\
\hline & & $\begin{array}{c}\text { Tên kiểu hệ sinh thái đất ngập } \\
\text { nước }\end{array}$ & $\begin{array}{l}\text { Ki hiệu } \\
\text { của Việt } \\
\text { Nam }\end{array}$ & $\begin{array}{l}\text { Ký hiệu } \\
\text { của } \\
\text { Ramsar }\end{array}$ & \\
\hline \multirow{3}{*}{$\begin{array}{c}\text { HST } \\
\text { ĐNN } \\
\text { TU̦ } \\
\text { NHÎ́N }\end{array}$} & \multirow{3}{*}{$\begin{array}{c}\text { HST } \\
\text { ĐNN } \\
\text { nội } \\
\text { địa }\end{array}$} & Sông, suối có nước thường xuyên & Stx & M & $\begin{array}{l}\text { Thưy văn - hài } \\
\text { văn }\end{array}$ \\
\hline & & $\begin{array}{l}\text { Vùng ngập nước có cây bụi chiếm } \\
\text { ưu thế và ngập nước theo mùa }\end{array}$ & $\mathrm{Cb}$ & W & $\begin{array}{l}\text { TTV, thưy văn } \\
\text { - hài văn }\end{array}$ \\
\hline & & $\begin{array}{l}\text { Vùng ngập nước có cây gỗ chiếm } \\
\text { ưu thế và ngập nước theo mùa }\end{array}$ & $\mathrm{Cg}$ & $\mathrm{Xf}$ & $\begin{array}{l}\text { TTV, thưy văn } \\
\text { - hài văn }\end{array}$ \\
\hline \multirow{4}{*}{$\begin{array}{c}\text { HST } \\
\text { ĐNN } \\
\text { NHÂN } \\
\text { TACO }\end{array}$} & \multirow{4}{*}{$\begin{array}{c}\text { HST } \\
\text { ĐNN } \\
\text { nhân } \\
\text { tạo }\end{array}$} & $\begin{array}{l}\text { Ao, hồ, đầm nuôi trồng thưy sản } \\
\text { nước ngot }\end{array}$ & Ann & 1,2 & TTV, HTSDÐ \\
\hline & & Đất canh tác nông nghiệp & Dnn & 3 & TTV, HTSDĐ \\
\hline & & Hồ chứa nước nhân tạo & Hnt & 6 & TTV, HTSDĐ \\
\hline & & Sông đào, kênh, mương, rạch & $\mathrm{Sd}$ & 9 & TTV, HTSDĐ \\
\hline
\end{tabular}

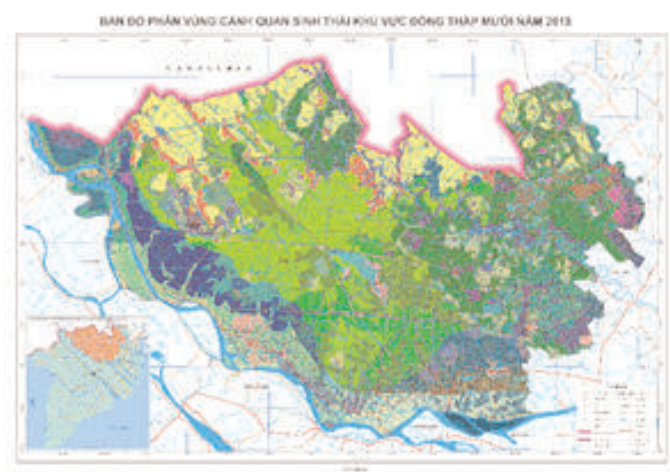

Hình 2: Bản đồ phân vùng cảnh quan sinh thái tỷ lẹ 1:100.000 khu vực Đồng Tháp Mười

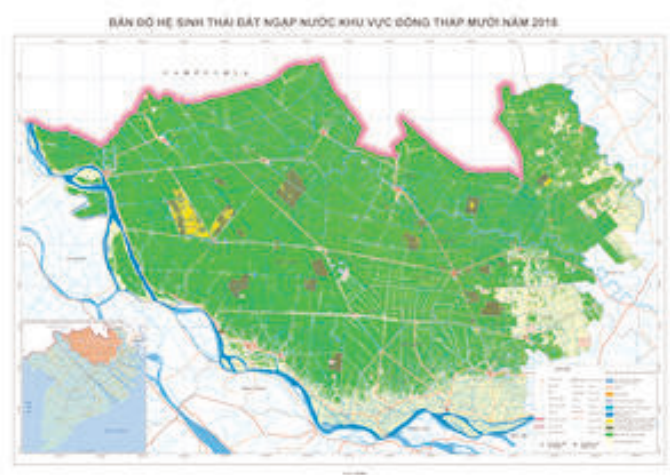

Hình 3: Bản đồ phân vùng HSTĐNN tỷ lệ 1:100.000 khu vưc Đồng Tháp Mười 
Bảng 2: Thống kê diện tích hệ sinh thái đất ngập nước khu vục Đồng Tháp Muời

\begin{tabular}{|c|c|c|c|c|c|}
\hline TT & Loại đối tượng & Số hiệu cảnh quan & Phân bố chũ yếu & Diện tích (ha) & $\begin{array}{l}\text { Tỷ lệ } \\
(\%)\end{array}$ \\
\hline I & \multicolumn{3}{|c|}{ Hệ sinh thái đất ngập nước } & $528.140,93$ & $78,69 \%$ \\
\hline 1 & \multicolumn{3}{|c|}{ HST ĐNN tur nhiên } & $57.722,45$ & $8,60 \%$ \\
\hline 1.2 & $\begin{array}{l}\text { Sông, suối có } \\
\text { nước thường } \\
\text { xuyên }\end{array}$ & 486 & $\begin{array}{l}\text { Hệ thống sông, } \\
\text { kềnh thuộc } 3 \text { tinh } \\
\text { như: Sông Tiền, } \\
\text { Sông Hậu. } \\
\end{array}$ & $35.195,15$ & $5,24 \%$ \\
\hline 1.3 & $\begin{array}{l}\text { Vùng ngập nước } \\
\text { có cây bưi chiếm } \\
\text { ưu thề và ngập } \\
\text { nươoc theo mùa }\end{array}$ & $\begin{array}{c}38,96,105,114,121,128,148,234 \\
249,261,269,283,402,415\end{array}$ & $\begin{array}{l}\text { Vườn quốc gia } \\
\text { Tràm Chim, xã } \\
\text { Binh Phong Thanh, } \\
\text { tập trung chú yếu ờ } \\
\text { huyện Tam Nông } \\
\end{array}$ & $4.513,34$ & $0,67 \%$ \\
\hline 1.4 & $\begin{array}{l}\text { Vùng ngẫ̂p nước } \\
\text { có cây gố chiếm } \\
\text { ưu thể và ngập } \\
\text { nước theo mưa }\end{array}$ & $\begin{array}{c}4,9,14,19,28,33,39,52,65,78,83, \\
88,97,102,106,107,115,122,129, \\
130,149,175,202,209,215,221,2 \\
28,250,256,262,263,270,276,28 \\
4,290,308,323,330,345,351,357, \\
363,369,374,378,387,396,403,4 \\
04,416,417,424,430,437,446,45 \\
2,458,464 . \\
\end{array}$ & $\begin{array}{l}\text { Vườn quốc gia } \\
\text { Tràm Chim, thu } \\
\text { bào tồn Láng Sen, } \\
\text { khu di tích Gáo } \\
\text { Giồng, xã Binh Hòa } \\
\text { Hưng, xã Vĩnh } \\
\text { Châu A. }\end{array}$ & $18.013,96$ & $2,68 \%$ \\
\hline 2 & \multicolumn{3}{|c|}{ HST ĐNN nhân tao } & $470.418,48$ & $70,09 \%$ \\
\hline 2.1 & $\begin{array}{l}\text { Đất canh tác nông } \\
\text { nghiệp }\end{array}$ & $\begin{array}{r}1,3,8,13,18,23,27,32,37,43,47,5 \\
1,56,57,61,64,69,73,77,82,87,92 \\
, 94,95,101,103,104,112,113,119 \\
, 120,126,127,135,136,137,141,1 \\
45,146,147,153,155,157,158,15 \\
9,160,163,166,169,173,174,179, \\
183,187,191,192,193,196,198,2 \\
00,201,207,208,214,219,220,22 \\
6,227,232,233,236,238,242,243, \\
247,248,255,259,260,267,268,2 \\
74,275,281,282,289,293,296,30 \\
0,303,305,307,313,314,318,321, \\
322,328,329,334,336,337,340,3 \\
42,344,349,350,355,356,361,36 \\
2,367,368,373,377,379,380,381, \\
382,385,386,390,394,395,400,4 \\
01,409,413,414,422,423,428,42 \\
9,435,436,441,444,445,450,451, \\
456,457,462,463 .\end{array}$ & \begin{tabular}{|l|l} 
Trài khắp & 3 tỉnh \\
Long An, Tiền \\
Giang, Đồng Tháp.
\end{tabular} & $454.562,69$ & $67,73 \%$ \\
\hline 2.2 & $\begin{array}{l}\text { Hồ chứa nước } \\
\text { nhân tạo }\end{array}$ & 468 & $\begin{array}{l}\text { Räi rác trong lhu } \\
\text { vực canh tác nông } \\
\text { nghiêp, lhu dân cư. }\end{array}$ & $1.067,29$ & $0,16 \%$ \\
\hline 2.3 & $\begin{array}{l}\text { Sồng đào, kênh, } \\
\text { mương, rạch }\end{array}$ & 468 & $\begin{array}{l}\text { Träi lhăp lhu dầ } \\
\text { cư, lhu canh tác } \\
\text { nông nghiẹp. }\end{array}$ & $7.279,22$ & $1,08 \%$ \\
\hline 2.4 & $\begin{array}{l}\text { Ao, hồ, đầm nuôi } \\
\text { trông thưy sản } \\
\text { nước ngợ }\end{array}$ & $\begin{array}{l}5,10,15,20,24,29,34,40,44,48,53 \\
, 58,62,66,70,74,79,84,89,98,108 \\
116,123,131,138,142,150,170,1 \\
76,180,184,188,194,203,210,21 \\
6,222,229,237,239,244,251,264, \\
271,277,285,291,297,301,306,3 \\
09,315,319,324,331,346,352,35 \\
8,364,370,375,391,397,405,410, \\
418,425,431,438,442,447,453,4 \\
59,465\end{array}$ & $\begin{array}{l}\text { Chư yêu ó ven các } \\
\text { kênh, sông }\end{array}$ & $7.509,28$ & $1,12 \%$ \\
\hline II & \multicolumn{3}{|c|}{ Đầt không ngạp nước } & $142.987,65$ & $21,31 \%$ \\
\hline 1 & Dân cư & 496 & $\begin{array}{l}3 \text { tinh Long An, } \\
\text { Tiền Giang, Đồng } \\
\text { Tháp. }\end{array}$ & $9.883,13$ & $1,47 \%$ \\
\hline 2 & Giao thông & 470 & $\begin{array}{l}3 \text { tinh Long An, } \\
\text { Tiền Giang, Đông } \\
\text { Tháp. }\end{array}$ & $16.808,10$ & $2,50 \%$ \\
\hline 3 & $\begin{array}{l}\text { Đất lhông ngập } \\
\text { nước }\end{array}$ & $\begin{array}{l}2,67,11,12,16,17,21,22,25,26,30 \\
31,35,36,41,42,45,46,49,50,54, \\
55,59,60,63,67,68,71,75,76,80,8 \\
1,85,86,90,91,93,99,100,109,11 \\
0,111,117,118,124,125,132,133, \\
134,139,140,143,144,151,152,1 \\
54,156,161,162,164,165,167,16 \\
8,171,172,177,178,181,182,185, \\
186,189,190,195,197,199,204,2 \\
05,206,211,212,213,217,218,22 \\
3,224,225,230,231,240,241,245, \\
246,252,253,254,257,258,265,2 \\
66,272,273,278,279,280,286,28 \\
7,288,292,294,295,298,299,302, \\
304,310,311,312,316,317,320,3 \\
25,326,327,332,333,335,338,33 \\
9,341,343,347,348,353,354,359, \\
360,365,366,371,372,376,383,3 \\
84,388,389,392,393,398,399,40 \\
6,407,408,411,412,419,420,421, \\
426,427,432,433,434,439,440,4 \\
43,448,449,454,455,460,461,46 \\
6,467 .\end{array}$ & $\begin{array}{l}\text { Phía Nam cuia } 3 \\
\text { huyện Cái Bè, Cai } \\
\text { Lầy, Cao Lânh cùng } \\
\text { hưyện Bên Lức, } 1 \\
\text { phân huyện Thủ } \\
\text { Thữa và Đức Huệ. }\end{array}$ & $116.296,42$ & $17,33 \%$ \\
\hline & Tông & & & 671.128 .59 & 100 \\
\hline
\end{tabular}


Đối với các kiểu hệ sinh thái không gọi tên được theo loại cảnh quan cần kết hợp bổ sung thêm các thông tin về hiện trạng sử dụng đất (HTSDĐ), thủy - hải văn và các thông tin khác có liên quan theo Quyết định 1093/QĐ-TCMT ngày 22/8/2016. (Xem bảng 1)

Sau khi chuẩn hoá, gán tên gọi các hệ sinh thái đất ngập nước theo lớp dữ liệu phân vùng cảnh quan sinh thái khu vực Đồng Tháp Mười, kết quả cho ra lớp dữ liệu bản đồ phân vùng hệ sinh thái đất ngập nước tỷ lệ 1:100.000 khu vực Đồng Tháp Mười (Hình 3).

Trên cơ sở kết hợp giữa 8 nhóm loại đất và 6 kiểu thảm thực vật của khu vực Đồng Tháp Mười đã xác định được 470 đơn vị loại cảnh quan, 03 HST nội địa, 04 HST nhân tạo (Bảng 2). Số liệu thống kê từ bản đồ cũng cho thấy, diện tích các hệ sinh thái đất ngập nước là 528.140,93 ha chiếm 78,69\%, trong đó, diện tích HST ĐNN tự nhiên là 57.722,45 ha chiếm $8,60 \%$, diện tích HST ĐNN nhân tạo là 470.418,48 ha chiếm 70,09\%. Diện tích đất không ngập nước là 142.987,65 ha chiếm 21,31\%. Cụ thể như sau: (Xem bảng 2)

Đất canh tác nông nghiệp chiếm tỷ trọng cao nhất là $67,73 \%$ trong tổng diện tích tự nhiên, phân bố rải rác khắp các huyện của 3 tỉnh Long An, Tiền Giang, Đồng Tháp thuộc khu vực Đồng Tháp Mười, Loại đất chủ yếu là đất phù sa, đất phèn thích hợp cho việc phát triển cây lúa, cây công nghiệp ngắn ngày.

Vùng ngập nước có cây bụi chiếm ưu thế ngập nước theo mùa chiếm $0,67 \%$ diện tích tự nhiên, phân bố chủ yếu ở huyện Tam Nông, Đồng Tháp. Vùng ngập nước có cây gỗ chiếm ưu thế ngập nước theo mùa phân bố rải rác tại một số khu sinh thái như vườn quốc gia Tràm Chim, khu du lịch sinh thái Gáo Giồng, chiếm 2,68\% diện tích tự nhiên.
Sông, suối có nước thường xuyên chiếm 5,24\% diện tích tự nhiên, gồm hệ thống sông Tiền, sông Hậu cùng các kênh phân bố trải khắp khu vực Đồng Tháp Mười.

Ao, hồ, đầm nuôi trồng thủy sản nước ngọt chiếm lần lượt $1,12 \%$ diện tích tự nhiên do hoạt động phát triển nuôi trồng thủy sản của người dân.

Sông đào, kênh, mương, rạch chiếm 1,08\%, hồ chứa nước nhân tạo chiếm $0,16 \%$ tỷ trọng tổng diện tích tự nhiên do hoạt động thủy lợi, xây dựng hồ chứa nước giúp cải thiện các vấn đề liên quan đến thủy lợi cho người dân sinhs hoạt và sản xuất.

Đất không ngập nước chiếm 17,33\% tổng diện tích tự nhiên, tập trung chủ yếu ở các khu vực gờ cao ven sông, địa hình cao của huyện Bến Lức, huyện Cái Bè, huyện Tân Phước, thành phố Cao Lãnh. Đây là các khu vực trồng một số loại cây lâu năm, đất trống... Các hệ sinh thái khác bao gồm dân cư, giao thông chiếm tỷ trọng lần lượt là $1,47 \%$ và $2,50 \%$.

\section{Kết luận}

Việc tiếp cận cảnh quan thành lập bản đồ phân vùng hệ sinh thái đất ngập nước Đồng Tháp Mười, với các yếu tố cấu thành là địa chất, thổ nhưỡng, địa hình - địa mạo, khí hậu - khí tượng, thuỷ văn - hải văn, thảm thực vật và hiện trạng sử dụng đất, giúp xác định ranh giới các hệ sinh thái đất ngập nước một cách khoa học. Đây sẽ là dữ liệu đầu vào cho công tác đánh giá mức độ đa dạng sinh học, các chức năng, dịch vụ, các áp lực rủi ro mà hệ sinh thái phải đối diện; xác định các hệ sinh thái bị suy thoái, từ đó làm cơ sở xác định các hệ sinh thái cần ưu tiên bảo vệ, phục hồi, giúp công tác quản lý của nhà nước trong phạm vi cấp vùng, liên tỉnh về đất ngập nước ngày càng hiệu quả hơn. $\bigcirc$ 


\section{Tài liệu tham khảo:}

[1]. Nguyễn Thuỳ Dương (2009). Nghiên cứu biến động cảnh quan và đa dạng sinh học đất ngập nước ven biển Thái Bình, định hướng quy hoạch sử dụng vùng cho phát triển bền vững. Luận án tiến sĩ Sinh thái học, Trường Đại học Khoa học Tự nhiên, Đại học Quốc gia Hà Nội.

[2]. Phạm Hoàng Hải, Nguyễn Thượng Hùng, Nguyễn Ngọc Khánh (1997). Cơ sở cảnh quan học của việc sử dụng hợp lí tài nguyên thiên nhiên, bảo vệ môi trường lãnh thổ Việt Nam. NXB Giáo dục, Hà Nội.

[3]. Vũ Tự Lập (1976). Cảnh quan địa lý miền Bắc Việt Nam. NXB Khoa học và Kỹ thuật, Hà Nội.

[4]. Nguyễn Thành Long và nnk (1993). Nghiên cứu xây dựng bản đồ cảnh quan các tỉ lệ trên lãnh thổ Việt Nam. Trung tâm Khoa học Tự nhiên và Công nghệ Quốc gia, Hà Nội.

[5]. Nguyễn Nguyệt Minh, Trương Quang
Hải, Nguyễn Ngọc Khánh (2013). Đặc điểm các đơn vị phân loại cảnh quan và phân vùng cảnh quan tỉnh Hà Tĩnh. Tạp chí khoa học Đại học Quốc gia Hà Nội - Các khoa học Trái đất và Môi trường, Tập 29, Số 4 (2013) 53-65.

[6]. Phạm Hạnh Nguyên, Trương Quang Hải, Lê Kế Sơn (2015). Đánh giá thích nghi sinh thái phục vụ phát triển kinh tế và bảo tồn rừng ngập mặn khu vực Mũi Cà Mau. Tạp chí Khoa học Đại học Quốc Gia Hà Nội: Các Khoa học Trái đất và Môi trường, Tập 31, Số 4, trang 29-40, Hà Nội, 2015.

[7]. Quốc hội Nước Cộng hoà Xã hội chủ nghĩa Việt Nam (2008). Luật Đa dạng sinh học, Hà Nội.

[8]. Vũ Trung Tạng (2015). Cơ sở sinh thái học. NXB Giáo dục Việt Nam, Hà Nội.

[9]. Hoàng Văn Thắng, Lê Diên Trực (2006). Hệ thống phân loại đất ngập nước Việt Nam. Cục bảo vệ môi trường, Hà Nội.

\section{Summary}

\section{Landscape approach - based wetland ecosystem mapping for Dong Thap Muoi region at 1:100.000 scale}

\section{Nguyen Thanh Thuy}

\section{Vietnam institute of geodesy and cartography}

Wetland ecosystem map is input data for assigning and assessing the biodiversity, functions, services, the risk pressures on, and the degradations of wetland ecosystems. The resulting map is used to define the wetland ecosystems protection and restoration prioritie orders. This paper shows the landscape approach - based wetland ecosystem map establishment methodology, for Dong Thap Muoi region at 1:100.000 scale for planning and managing at the regional and inter-provincial level, with the forming factors, are geology, soil, topography - geomorphology, climate - meteorology, hydrology-oceanography, vegetation, and land use status. $\bigcirc$ 